Journal of Computer Science 6 (7): 689-692, 2010

ISSN 1549-3636

(C) 2010 Science Publications

\title{
A System for E-Learning Processes Management
}

\author{
Hassan Mohammed M. Elmetwaly \\ Department of Computer Science and Information Technology, King Faisal University, \\ P.O. Box 64834, Riyadh 11546, Kingdom of Saudi Arabia
}

\begin{abstract}
Problem statement: This research deled with difficulties and challenges facing students in their seek to reach specialized courses and curriculums. Approach: It also deled with methodology of facing such challenges and difficulties and hence facilitating process of allowing such data and information to all beneficiaries, either they are student, trainees or educational organization all over the world. Results: E-learning system comprised a number of processes such as school curriculum, teaching methods, educational activities, educational schemes and various means of education. Conclusion/Recommendations: This system supported both teacher, students, employees and administrators reach easily and fast to various aspects of educational domains in all fields of study. Through going directly to control panel of the system and using oracle database and ASP, they can manage all previous operations implemented by academics and specialists in this field.
\end{abstract}

Key words: E-learning system, E-systems, ORACLE, SQL, ASP .NET, web-based

\section{INTRODUCTION}

Process of developing means and tools of education is deemed to be one of the most critical objectives for professionals in this domain. This research discusses how to utilize modern technologies available and Oracle databases to be available in early future, to be both utilized and exchanged among concerned parties. Further, multimedia shall be utilized in education. Audio and video will also be utilized. The sole purpose will be reaching multimedia educational environment through developing good interactive educational tools. System of e-learning tends to increase productivity in the field of education as it provides major opportunities for obtaining educational materials at any time and under any circumstances any where all over the globe. This id accomplished through internet deemed now to be a component of daily life serving both students and teachers all over the entire world. Therefore, to make e-learning more effective and efficient some useful techniques are used to implement and design an evaluation approach which is truly based on some factors which are evaluated thoroughly like content related factors, communication related factors (Ketabchi et al., 2008). The most Elearning monitoring and evaluating system based on questionnaires which have been widely used for both evaluating affect and usability of interactive systems (Zaharias and Poylymenakou, 2009). The electronic learning system is evaluated for three main components: The usability evaluation to cover the graphical user interface, easy to use, helpfulness and alertness; the fulfillment evaluation to examine the features incorporated in terms of reusability, interoperability, durability and accessibility and the overall satisfaction (Ganchev et al., 2007). A wide and strong set of rules of dependencies among users, methods and learning objects is needed to describe these eight types of adaptation and moreover their possible combinations (Karampiperis and Sampson, 2004). We define adaptive E-learning as a method to create a learning experience to the student, but also to the tutor, based on the configuration of a set of elements in a specific period aiming to increase of the performance of a pre-defined criteria (Van Rosmalen et al., 2006). Content-based, where resources and activities dynamically change their actual content, as in Adaptive and Intelligent Web-Based Educational Systems based on adaptive Presentation (Brusilovsky and Miller, 2001). evaluate its actual usage in a real working environment by analyzing the learners' behaviors and results (Markham et al., 2003).

\section{MATERIALS AND METHODS}

On designing system of e-learning, it is considered that one of its major objectives will be to satisfy needs of both students and trainees. This is one of the core objectives of researchers and professionals in this domain. Along the latest years, new training methods and ideas for internet-based education were reached. Oracle databases supported all professionals in 
educational domains either as programmers and developers of databases to develop and maintain all information either in form of scientific, academic or specializes lessons. Through this system it might be possible to register applications, admissions and hence to know schedules and results of tests. Further, an addition of questionnaires might be implemented or uploaded to internet for the purpose of supporting decision makers evaluate study and know about opinions of all users, students and trainees and try to eliminate obstacles and difficulties they might be exposed to. A wide and strong set of rules of dependencies among users, methods and learning objects is needed to describe these eight types of adaptation and moreover their possible combinations (Karampiperis and Sampson, 2004). On the other hand, the categories in the proposed system are originally concentrated. When a new node joins the system, not only location information of a category but the category itself must be handed to the new node. Considering that, the P2P network of the proposed system can be constructed as a CAN (Ratnasamy et al., 2001). We have proposed and implemented a distributed Elearning system based on P2P architecture (Kawamura and Sugahara, 2005). Interactive experience for the user, i.e., instructors and learners is defined as 'a multidimensional, multi-sensory interweave of self-directed reading, viewing, listening and interacting, through activities such as exploring, searching, manipulating, writing, linking, creating, juxtaposing and editing (Wilson, 1992). Each approach considers indicators according to their context and in some cases in the same study, units of measurement are different, hinders their analysis (Ga-Jin, 2007).

\section{RESULTS}

- Database used is Oracle

- Data entry is implemented by pre-designed forms and applications

- It is necessary to use multimedia in training and education

- Lectures shall be recorded in video formats then uploaded to internet

- It is possible to reach scientific lessons easily and fast

- To facilitate process of participation of academics and specialists in this field and possibility to take their notices and consider their remarks

- Adding e-questionnaires to list of services provided

- All forms and reports to be uploaded to internet shall be designed by ASP

\section{DISCUSSION}

E-learning passes several phases including, first, the phase of preparing lectures and scientific classes processed by professors and specialists in this domain. The second phase is the phase of transforming those classes and training courses into electronic data. This is implemented through inserting them in concerned forms. The third phase is the one concerned with follow up. In this phase specialists are assigned to follow up in the same respect. The fourth phase concerns with evaluation of lectures and classes. The firth phase is the one concerned with development in which all classes and lectures are developed in a manner that most suits practical life changes. The sixth phase is the phase of technical support (Fig. 1). Figure 2 shows table lessons in database they are a model of some schedules used in information systems and that had been structured by oracle developer create table lessons example. Figure 3 shows the relationship between lessons table and teacher table. Figure 4 shows lessons table sequence in oracle database. Figure 5 shows primary key, unique constraints. Figure 6 shows E-learning over view. Figure 7 shows student registration form. Figure 8 shows lessons registration form.

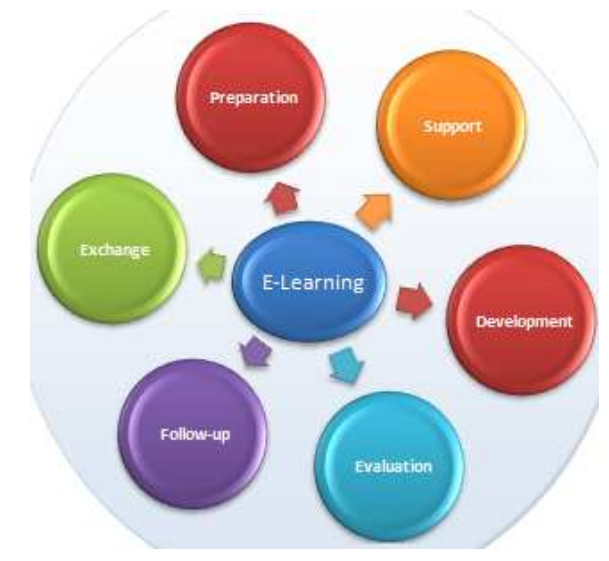

Fig. 1: E-learning processes

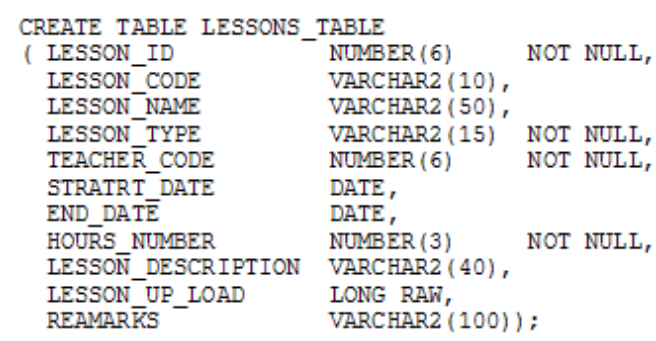

Fig. 2: Table lessons in database 
ALTER TABLE LESSONS TABLE

ADD CONSTRAINT LESSONNS_TEACHER_CODE

FOREIGN KEY (TEACHER CODE)

REFERENCES TEACHERS_TABLE (TEACHER_CODE) ;

Fig. 3: Relationship between lessons table and teacher table

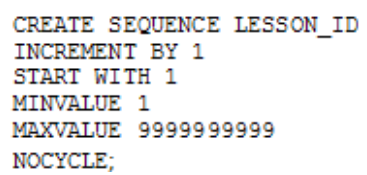

Fig. 4: Lessons table sequence

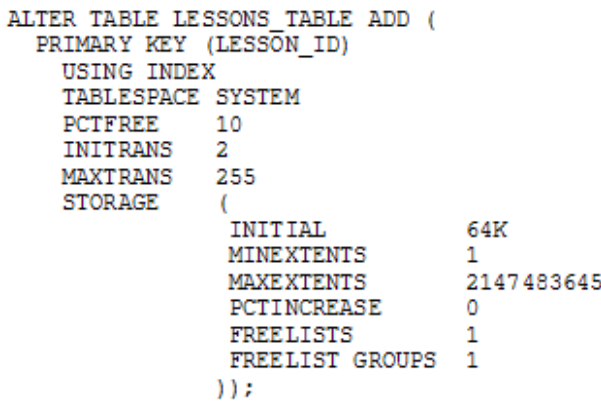

Fig. 5: Primary key, unique constraints

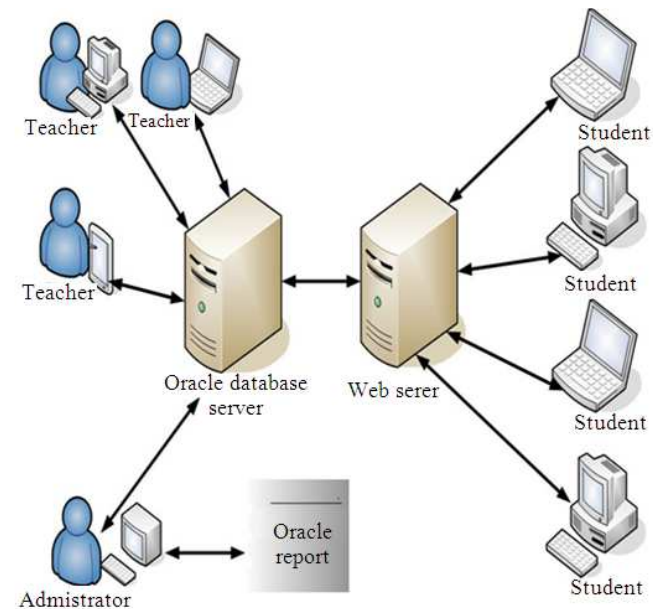

Fig. 6: E-learning over view

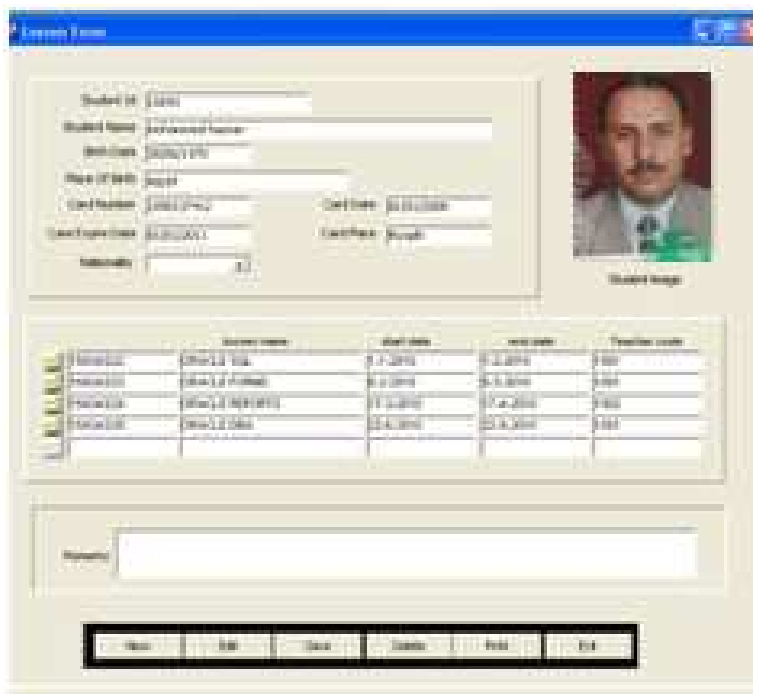

Fig. 7: Student registration form

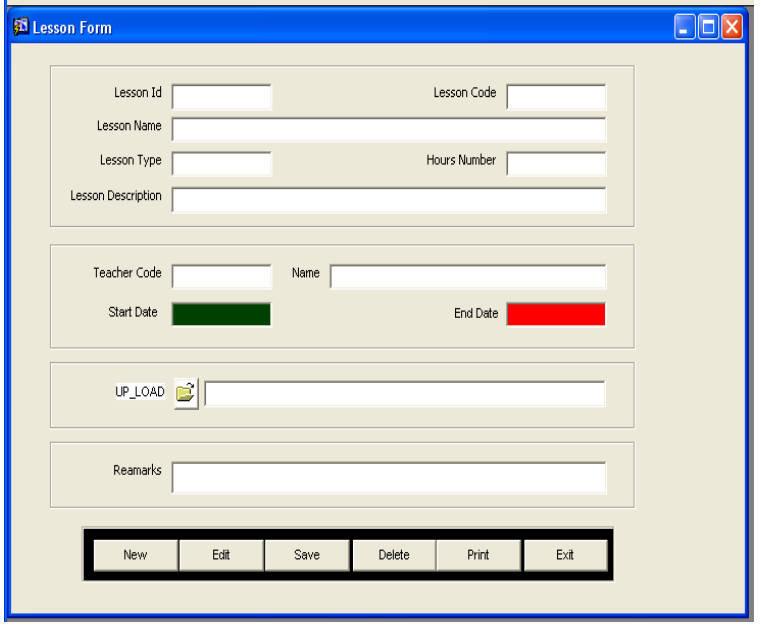

Fig. 8: Lessons registration form

\section{CONCLUSION}

The core objective of proposed e-learning is to facilitate the process of connecting students, trainees with teachers and professors. Oracle SQL databases are used due to its excellence in capacity of data volumes that can be uploaded, number of users who can access to databases ate any time. Following up the latest news and events in relation to educational processes. This is accomplished through information systems structured. Further, it enables student upload his remarks and suggestions through pre-designed internet questionnaires. A student might also be able to download all lectures and classes from web site that 
shall be the connection joint between student and instructor. All educational means were utilized in teaching and learning this included video recording and uploading to internet website in addition to using charts and animations in instruction. We can say that it is possible to reach lessons and lectured in easier and faster manner within reach of all concerned parties.

\section{REFERENCES}

Brusilovsky, P. and P. Miller, 2001. Course Delivery Systems for the Virtual University. In: Access to Knowledge: New Information Technologies and the Emergence of the Virtual University, Tschang, F.T. and T. Della Senta (Eds.). Elsevier Science and International Association of Universities, Amsterdam, pp: 167-206.

Ga-Jin, I., 2007. Developing evaluation tool for elearning. Proceeding of the Portland International Center for Management of Engineering and Technology, Aug. 5-9, IEEE Xplore Press, Portland, OR., pp: 1526-1537. DOI: 10.1109/PICMET.2007.4349475

Ganchev, I., M. O’Droma and R. Andreev, 2007. Functionality and SCORM-compliancy evaluation of e-learning tools. Proceeding of the 7th IEEE International Conference on Advanced Learning Technologies, July 18-20, IEEE Xplore Press, Niigata, pp: 467-469. DOI: 10.1109/ICALT.2007.149

Karampiperis, P. and D. Sampson, 2004. Adaptive learning object selection in intelligent learning systems. J. Interact. Learn. Res., 15: 389-408.

Kawamura, T. and K. Sugahara, 2005. A mobile agentbased P2P e-learning system. IPSJ J., 46: 222-225.
Ketabchi, E., M. Mortazavi and A. Moeini, 2008. Evaluation of user satisfaction in center of learning University of Tehran. Proceeding of the International Conference on Computer Science and Software Engineering, Dec. 12-14, IEEE Computer Society, Washington DC., USA., pp: 536-539. DOI: 10.1109/CSSE.2008.1513

Markham, S., J. Ceddia, J. Sheard, C. Burvill and J. Weir et al., 2003. Applying agent technology to evaluation tasks in e-learning environments. Proceedings of the Exploring Educational Technologies Conference, July 16-17, Monash University, Melbourne, Australia, pp: 31-3.

Ratnasamy, S., P. Francis, M. Handley, R. Karp and S. Schenker, 2001. A scalable content-addressable network. Proceedings of the 2001 Conference on Applications, Technologies, Architectures and Protocols for Computer Communications, (ATAPCC'01), ACM Press, San Diego, California, United States, pp: 161-172. http://portal.acm.org/citation.cfm?id=383072

Van Rosmalen, P., H. Vogten, R. van Es, P. van and H.P. Poelmans et al., 2006. Authoring a full life cycle model in standards-based, adaptive elearning. Educ. Technol. Soc., 9: 72-83.

Wilson, K., 1992. Discussion on Two Multimedia R and D Projects: The Plaenque Project and the Interactive Video Project of the Museum Education Consortium. In: Interactive Multimedia Learning Environments, Girdina M. (Ed.). Springer-Verlag, Berlin, pp: 186-196.

Zaharias, P. and A. Poylymenakou, 2009. Developing a usability evaluation method for e-learning applications: Beyond functional usability. Int. J. Hum-Comput. Interact., 25: 75-98. DOI: 10.1080/10447310802546716 